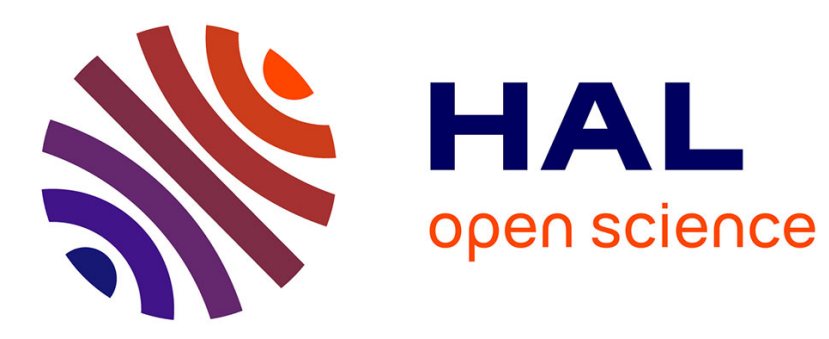

\title{
Storm damage of Douglas-fir unexpectedly high compared to Norway spruce
}

\author{
Axel Albrecht, Ulrich Kohnle, Marc Hanewinkel, Jürgen Bauhus
}

\section{To cite this version:}

Axel Albrecht, Ulrich Kohnle, Marc Hanewinkel, Jürgen Bauhus. Storm damage of Douglas-fir unexpectedly high compared to Norway spruce. Annals of Forest Science, 2013, 70 (2), pp.195-207. 10.1007/s13595-012-0244-x . hal-01201464

\section{HAL Id: hal-01201464 \\ https://hal.science/hal-01201464}

Submitted on 17 Sep 2015

HAL is a multi-disciplinary open access archive for the deposit and dissemination of scientific research documents, whether they are published or not. The documents may come from teaching and research institutions in France or abroad, or from public or private research centers.
L'archive ouverte pluridisciplinaire HAL, est destinée au dépôt et à la diffusion de documents scientifiques de niveau recherche, publiés ou non, émanant des établissements d'enseignement et de recherche français ou étrangers, des laboratoires publics ou privés. 


\title{
Storm damage of Douglas-fir unexpectedly high compared to Norway spruce
}

\author{
Axel Albrecht • Ulrich Kohnle • Marc Hanewinkel • \\ Jürgen Bauhus
}

Received: 14 February 2012 / Accepted: 17 September 2012 / Published online: 9 October 2012

(C) INRA and Springer-Verlag France 2012

\begin{abstract}
- Context Since storm damage has a large impact on forest management in Central Europe, we investigated the main storm risk factors for two important conifer species, Douglas-fir (Pseudotsuga menziesii [Mirbel] Franco) and Norway spruce (Picea abies [L.] Karst.).

- Aims We compared general storm damage levels of Douglas-fir and Norway spruce, the latter being known to have high storm risk among European tree species.

- Methods Generalized linear mixed models and boosted regression trees were applied to recorded storm damage of individual trees from long-term experimental plots in southwest Germany. This included two major winter storm events in 1990 and 1999. Over 40 candidate predictors were tested for their explanatory power for storm damage and summarized into predictor categories for further interpretation.

- Results The two most important categories associated with storm damage were timber removals and topographic or site information, explaining between 18 and $54 \%$ of storm damage risk, respectively. Remarkably, general damage levels were not different between Douglas-fir and Norway spruce.
\end{abstract}

Handling Editor: Barry Alan Gardiner

\author{
A. Albrecht $(\bowtie) \cdot$ U. Kohnle \\ Department of Forest Growth, \\ Forest Research Institute Baden-Wuerttemberg, \\ Wonnhaldestr. 4, \\ 79100 Freiburg, Germany \\ e-mail: axel.albrecht@forst.bwl.de
}

\section{Hanewinkel}

Swiss Federal Institute for Forest, Snow and Landscape Research,

Zürich, Switzerland

J. Bauhus

Institute of Silviculture, University of Freiburg,

Freiburg im Breisgau, Germany
- Conclusion Under current forest management approaches, Douglas-fir may be considered a species with high storm risk in Central Europe, comparable to that of Norway spruce.

Keywords Storm damage · Risk · Windthrow · Douglas-fir . Norway spruce $\cdot$ Southwest Germany $\cdot$ Empirical modeling

\section{Introduction}

According to the second National Forest Inventory, Douglas-fir (Pseudotsuga menziesii [Mirbel] Franco) covered no more than $1.6 \%$ of Germany's forest area in 2002. However, between the first (1987) and the second inventory (2002), its share had increased from $1.1 \%$, while the area of most other coniferous species had decreased during the same period. As an introduced species, Douglas-fir is especially present in forests younger than 40 years to which it contributes close to $5 \%$ of the area (BMVEL 2006).

Douglas-fir's increasing importance in managed forests in Germany as well as in other European countries is based, among others, on its high productivity (Heidingsfelder and Knoke 2004), its favorable wood properties, and its large physiological adaptability with regard to site conditions including drought tolerance. Especially under increasing temperatures and longer water stress periods in summer-as expected under future climate change (Enke et al. 2005; Stock 2005)-Douglas-fir is discussed as an alternative to other economically important conifers. For example, Norway spruce (Picea abies [L.] Karst.) is facing reduced vitality and a significant reduction in area due to difficulties in coping with increasing temperatures (Spiecker et al. 1996).

In addition to climatic change, the vulnerability of tree species to storm damage is another important aspect involved in decisions about tree species selection and forest management. In this context, it should be recognized that storms causing catastrophic damage in the forests of Central 
Europe are predominantly winter storms from the North Atlantic Ocean (Leckebusch et al. 2006). Deciduous species have a generally lower drag than conifers and show better streamlining in the wind (Rudnicki et al. 2004; Vollsinger et al. 2005). Among the coniferous species, Norway spruce is frequently ranked as the most vulnerable species with respect to storm damage (Bouchon 1987; Colin et al. 2009; Mayer et al. 2005; Schmidt et al. 2010). Norway spruce's high vulnerability has been attributed to its shallow rooting characteristics and cultivation outside its natural range, such as on unsuitable sites (e.g., waterlogged soils) and in monospecific stands (Von Teuffel et al. 2004). It is thus a combination of site, stand, and true species-level effects rendering Norway spruce vulnerable.

In the natural range of Douglas-fir in the Pacific Northwest of North America, wildfires are the most important abiotic disturbance agent in Douglas-fir forests and storm damage occurs much less frequently (Johnson et al. 2010). Unfortunately, to our knowledge, no comprehensive study has yet been conducted specifically addressing storm risk of Douglas-fir within its natural range. Nevertheless, the species appears to be considered of medium storm risk and is generally neither rated among the top critical nor the top resistant species (e.g., McComb et al. 1993).

Owing to its recent forestry use in Europe on a larger scale, there is very limited quantitative information about the susceptibility of Douglas-fir to storm damage (Colin et al. 2009; Riou-Nivert 2003). However, empirical knowledge of advantageous properties of Douglas-fir concerning wind stability and favorable practical experiences lead forest managers in Europe to expect a higher wind resistance compared to Norway spruce. These advantageous properties include a stronger stem and deeper rooting (Groth 1927; Hermann 2005; McMinn 1963; Nicoll et al. 2006; Studholme 1995). Compared to Sitka spruce (Picea sitchensis [Bong.] Carrière), Douglas-fir also shows smaller drag (Mayhead 1973).

In addition to species-specific attributes, other important risk factors considered to influence storm damage are stand or tree dimension (e.g., height or taper; Cucchi et al. 2005), site characteristics, and the impact of silvicultural treatments. In cases where height information is not available, some studies use age or diameter information as proxies for height (Rich et al. 2007). Yet height refers directly to leverage phenomena associated with wind loads, bending, and storm risk and is, therefore, the preferable predictor (Hanewinkel 2005).

Site-specific factors related to the risk of storm damage comprise soil texture and water regime (e.g., Schmidt et al. 2010) which influence vertical root penetration probably due to the lack of oxygen, strong soil acidity (Mayer et al. 2005) impeding fine root growth, and free calcium carbonate (Schmid-Haas and Bachofen 1991) which is known to destabilize Norway spruce due to increased formation of root rot. Soils with heavy clay as well as shallow, rocky soils with restricted rooting depth have been analyzed and discussed as site-related storm risk factors, however, with differing results (Quine 1995).

Silvicultural treatments such as thinnings have an influence on stand vulnerability (Cremer et al. 1982; Quine 1995). Other factors may also play a role for storm damage, but the four mentioned groups of factors including tree species, tree dimensions, site attributes, and silvicultural treatment of stands appear as the most important determinants.

The relative importance of these risk factor groups is quite difficult to determine, since different studies have been based on different data sources. Large-scale storm damage analyses usually have a more limited range of information on forest attributes. In turn, small-scale case studies may be based on detailed forest attributes, but their landscape-scale variability of geological or topographic characteristics is restricted. However, besides these difficulties, it is desirable for scientists and forest managers to be able to judge the relative magnitude of influence for the different groupings of factors on storm risk. For forest managers, this knowledge can lead to improved management decisions for reducing storm risk, including the choice of tree species, target diameters or rotation ages, and appropriate silvicultural treatment or thinning regimes.

Based on these considerations, the objective of the study was to investigate differences in storm resistance between Douglasfir and Norway spruce based on a large dataset of intensively surveyed long-term experimental plots in southwest Germany. To achieve this objective, we posed two hypotheses $(\mathrm{H} 1, \mathrm{H} 2)$ :

H1: The predictor "species" is as significant for storm damage as other predictors.

H2: Storm damage in Douglas-fir occurs less frequently than in Norway spruce.

\section{Material and methods}

The analyzed database comprised the network of long-term forest growth research plots in southwest Germany and consists of roughly 1,300 plots with an average size of 0.25 ha. The majority of the experimental plots examine the effects of different silvicultural treatments (e.g., regeneration, spacing, thinning) or of provenance on growth. While many different tree species are represented by these long-term plots, we selected Douglas-fir and Norway spruce plots for this study. The selected stands originated predominantly from planting and are monospecific and rather homogenous in structure. In addition, we focused on the two observation periods during which major storm events had occurred. Those were the storms in February 1990 (storm "Vivian/Wiebke") and December 1999 (storm "Lothar").

Measurements on the long-term research plots are commonly repeated in 5-year intervals to monitor periodic 
height and diameter increment. These measurements are performed at the individual tree level and the silvicultural treatments are performed within the same year as the measurement. If a tree is subject to mortality, the field crew will assign it a cause of mortality, e.g., scheduled harvesting or storm damage. With this cause of mortality, it was possible to differentiate between scheduled removals, which were in accordance with the treatment plan of the experiment, and nonscheduled removals (salvage), which occurred due to abiotic and biotic disturbance in an unsystematic and unplanned manner (storm, insect, or drought damage, etc.).

For every plot, the most recent data measurement before each of the two storm events was selected to represent stand conditions prior to the storm. The trees which were damaged by the following storm were then coded as event ("1"), the remaining trees as nonevents ("0"). Unfortunately, stem breakage and uprooting were not recorded separately. The tree-level damage code was summarized at the stand level and calculated as the relative storm damage $\left(P_{\text {Dam }}=\right.$ basal area of storm-damaged trees/total stand basal area prior to the storm event). The final dataset contained 700 plots covering 189 ha, irregularly spaced throughout southwest Germany. On these plots, 142,543 tree observations were recorded.

There were 42 candidate predictor variables comprising dendrometric characteristics, soil properties, and site information such as geographic position and topographic exposure. Additionally, we tested modeled wind gust speed data that were calculated for both storm events and a long-term average gust speed with the mesoscale model KAMM at a ground resolution of 1,000 $\mathrm{m}$ (Heneka et al. 2006). Table 1 gives a complete overview of the candidate predictors, including their assignment to different variable categories and a short description. Unique features of the predictor set compared to previous studies are that data on the stand level were derived from precise tree-level attributes and that quantitative information about the long-term development of plots is available, including past silvicultural treatment.

Some more explanation is needed concerning the variable category "removals." All variables labeled thinning quotient (ThQuot) were calculated as $\operatorname{Dg}_{\text {th }} \times \mathrm{Dg}^{-1}$, where $\mathrm{Dg}$ is the mean quadratic diameter prior to thinning and $\mathrm{Dg}_{\text {th }}$ is the $\mathrm{Dg}$ of only the removed trees. Values of the ThQuot greater than 1 indicate thinning from above, while values smaller than 1 stand for thinning from below. Some variables in this category were calculated in two ways: one version referring to all removals, while the other version referring only to the scheduled removals (i.e., relRem, relRem sched). This differentiation was possible due to the tree-level attribute "cause of removal" and served for testing whether effects of scheduled removals were different from effects of all removals, including scheduled and salvage removals.

Since single tree-level attributes have been shown to be much less important than stand-level attributes for the analyzed research plots (Albrecht 2009), we chose to analyze storm damage only at the stand level. The stand-level storm damage data consisted of 1,167 plot observations, 567 of which showed damage and 67 with total stand damage. Most plots were observed for both storm events, even if the plot had suffered partial damage in the first storm in 1990. Some plots even showed partial damage in both storm events. Only if a plot had been totally damaged in 1990 it was not observed again in the 1999 storm. The frequency distribution of damage was characterized by many plots without damage (as is typical for rare events), a negative exponential decrease up to values of $60 \%$ damage, and finally, a reincrease of plots with damage between 75 and $100 \%$ (Fig. 1). This U-shaped frequency distribution with zero inflation does not belong to the family of exponential or normal distributions and necessitated special analytical methods.

\subsection{Preliminary analysis}

In a preliminary analysis, we compared Norway spruce and Douglas-fir plots concerning stand, site, and silvicultural characteristics. This comparison included pairwise (Douglas-fir/Norway spruce) graphs and tables of the candidate predictors testing for univariate species differences in the raw data. This first step was necessary to examine whether potential species-specific effects may be influenced by differences in other potentially important factors. Results are shown for the most important factors stand height, thinning quotient, relative removals, and site characteristics.

To avoid confounding findings due to applying one single methodological approach only, further investigations applied two different statistical approaches. We applied generalized linear mixed models (GLMM) and boosted regression trees (BRT). These techniques were chosen since they allow the analysis of non-normal response distributions like that of $P_{\text {Dam }}$, mixed types of candidate predictors (metric, categorical, and nominal), and correlated observations, all being constraints which we were facing in the analyzed database. More explanation on the suitability and advantages/disadvantages of the chosen methods is given in the respective methods' sections. Both methods are based on the transformation of the mean of a binary response with the logit link (see Eq. 1, Logit $(\pi)=\log [P /(1-P)])$.

\subsection{Generalized linear mixed models}

Equation 1 shows the general formulation of a GLMM:

$\operatorname{Logit}(\pi)=x^{\prime} b+z^{\prime} \gamma$

GLMMs consist of two components: fixed and random effects. The fixed effects are the classical predictors (see Eq. $\left.1, x^{\prime}\right)$ of multiple regressions with their estimated coefficients 
Table 1 Summary statistics of the candidate predictors

\begin{tabular}{|c|c|c|c|c|c|}
\hline Variable name & Variable description & Mean & Number & $\mathrm{SD}$ & Variable category \\
\hline $\mathrm{H}_{2}$ Osat_1990 & Relative water saturation in soil 28 Feb 1990 & 0.95 & 1,167 & 0.12 & Meteorology \\
\hline $\mathrm{H}_{2}$ Osat_1999 & Relative water saturation in soil 26 Dec 1999 & 0.98 & 1,167 & 0.12 & Meteorology \\
\hline wind50 & $\begin{array}{l}\text { Wind50 (maximum gust speed in } \mathrm{m} / \mathrm{s} \text { with exceedence } \\
\text { probability of } 0.02 \text {, wind model KAMM) }\end{array}$ & 38.12 & 1,165 & 3.08 & Meteorology \\
\hline wind90 & $\begin{array}{l}\text { Wind } 90 \text { (maximum gust speed in } \mathrm{m} / \mathrm{s} \text { on } 28 \mathrm{Feb} 1990 \text {, } \\
\text { wind model KAMM) }\end{array}$ & 35.89 & 1,165 & 4.00 & Meteorology \\
\hline wind 99 & $\begin{array}{l}\text { Wind } 99 \text { (maximum gust speed in m/s on } 26 \text { Dec } 1999 \text {, } \\
\text { wind model KAMM) }\end{array}$ & 35.62 & 1,165 & 3.39 & Meteorology \\
\hline PreviousStormDamage & Previous storm damage (yes/no) & 0.19 & 1,167 & 0.39 & Previous storm damage \\
\hline relcumRemovals & Cumulative removals in percent of total volume production & 0.34 & 1,167 & 0.16 & Removals \\
\hline relRem & Relative removed volume & 0.14 & 1,167 & 0.12 & Removals \\
\hline relRem_10yr & $\begin{array}{l}\text { Average relative removed volume during past } 10 \text { years prior } \\
\text { to intervention }\end{array}$ & 0.13 & 1,167 & 0.09 & Removals \\
\hline relRem_prevTh & Relative removed volume of previous intervention & 0.13 & 1,167 & 0.12 & Removals \\
\hline relRem_sched & Relative removed volume of scheduled thinnings & 0.09 & 1,167 & 0.11 & Removals \\
\hline Rem & Absolute removed volume per ha (in $\mathrm{m}^{3}$ ) & 55.60 & 1,167 & 53.86 & Removals \\
\hline Rem_prevTh & Absolute removed volume of previous intervention per ha (in $\mathrm{m}^{3}$ ) & 52.21 & 1,167 & 55.54 & Removals \\
\hline Rem_sched & Absolute removed volume per ha of scheduled thinnings (in $\mathrm{m}^{3}$ ) & 35.32 & 1,167 & 44.14 & Removals \\
\hline ThQuot & Thinning quotient & 0.74 & 1,167 & 0.33 & Removals \\
\hline ThQuot_10yr & Average thinning quotient during past 10 years prior to intervention & 0.73 & 1,167 & 0.26 & Removals \\
\hline ThQuot_prevTh & Thinning quotient of previous intervention & 0.71 & 1,167 & 0.34 & Removals \\
\hline ThQuot_sched & Thinning quotient scheduled thinnings & 0.67 & 1,167 & 0.56 & Removals \\
\hline ThQuot_yrs & Thinning quotient/years since previous thinning & 0.02 & 1,167 & 0.03 & Removals \\
\hline yrssince_prevTh & Years since previous intervention & 4.90 & 1,167 & 1.97 & Removals \\
\hline acidicSoil & Strong acidity in upper soil $(<40 \mathrm{~cm}$; yes/no $)$ & 0.17 & 1,161 & 0.38 & Soil \\
\hline $\mathrm{CaCO}_{3}$ & Free $\mathrm{CaCO}_{3}$ in upper soil (<30 cm; yes/no) & 0.11 & 1,161 & 0.31 & Soil \\
\hline shallowSoil & Restricted rooting depth (bedrock $<40 \mathrm{~cm}$; yes $/$ no) & 0.07 & 1,156 & 0.25 & Soil \\
\hline StabPt & $\begin{array}{l}\text { Site risk score (stagnant water } \times 3+\text { restricted rooting } \times 2+ \\
\mathrm{CaCO}_{3}+\text { acidity) }\end{array}$ & 0.62 & 1,156 & 1.03 & Soil \\
\hline deepLoam & Loam >70 cm depth without bedrock or stones (yes/no) & 0.44 & 1,167 & 0.50 & Soil \\
\hline heavyClay & Over $50 \%$ clay horizons in the upper $70 \mathrm{~cm}$ (yes/no) & 0.03 & 1,167 & 0.18 & Soil \\
\hline waterloggedSoil & Stagnant water in soil $(<70 \mathrm{~cm}$; yes $/ \mathrm{no})$ & 0.07 & 1,161 & 0.25 & Soil \\
\hline Species & Main tree species (Douglas-fir: $N=531$, Norway spruce: $N=636$ ) & Nominal & 1,167 & & Species \\
\hline hd100 & $\mathrm{h} 100 / \mathrm{d} 100$ ratio & 0.70 & 1,167 & 0.07 & Stand density \\
\hline hd100_5rel & Relative 5-year h100/d100 ratio & 1.01 & 1,167 & 0.10 & Stand density \\
\hline hd100_relnorm & Relative normalized h100/d100 ratio & 0.98 & 1,167 & 0.10 & Stand density \\
\hline hd100_relnorm_5rel & Relative 5-year normalized h100/d100 ratio & 1.00 & 1,167 & 0.09 & Stand density \\
\hline stockDegr & Stock density & 0.88 & 1,149 & 0.21 & Stand density \\
\hline D100 & Mean quadratic diameter of 100 largest trees per ha & 35.13 & 1,167 & 9.90 & Stand dimension \\
\hline $\mathrm{Dg}$ & Mean quadratic diameter & 27.25 & 1,167 & 9.73 & Stand dimension \\
\hline G & Basal area per ha (in $\mathrm{m}^{2}$, trees with $\mathrm{dbh}>6.5 \mathrm{~cm}$ ) & 32.32 & 1,167 & 9.43 & Stand dimension \\
\hline H100 & Dominant height & 24.52 & 1,167 & 7.17 & Stand dimension \\
\hline $\mathrm{Hg}$ & Mean height & 22.72 & 1,167 & 7.18 & Stand dimension \\
\hline $\mathrm{N}$ & Number of stems per ha (trees with $\mathrm{dbh}>6.5 \mathrm{~cm}$ ) & 676.15 & 1,167 & 388.95 & Stand dimension \\
\hline stand_age & Age of main tree species & 50.20 & 1,154 & 29.87 & Stand dimension \\
\hline $\mathrm{V}$ & Standing volume per ha (in $\mathrm{m}^{3}$, trees with $\mathrm{dbh}>6.5 \mathrm{~cm}$ ) & 410.02 & 1,167 & 201.19 & Stand dimension \\
\hline Dist_2ForEdge & Distance to westward forest edge in $\mathrm{m}(\leq 340 \mathrm{~m})$ & 304.52 & 1,166 & 79.33 & Topography and site \\
\hline elevation & Elevation above sea level (m) & 567.16 & 1,166 & 210.78 & Topography and site \\
\hline Topex $8 w$ & Topex (distance $1,000 \mathrm{~m}$, west weighted, 8 cardinal directions) & 21.82 & 1,165 & 29.97 & Topography and site \\
\hline
\end{tabular}

The thinning quotient was calculated as the mean quadratic diameter of removed trees/the mean quadratic diameter of all trees prior to thinning 
Fig. 1 Histogram of the standlevel storm damage percentage (basal area) for the two examined storm events in 1990 and 1999: a for all plots and b only for plots with damage $>5 \%$. NorwSpr Norway spruce, DglFir Douglas-fir
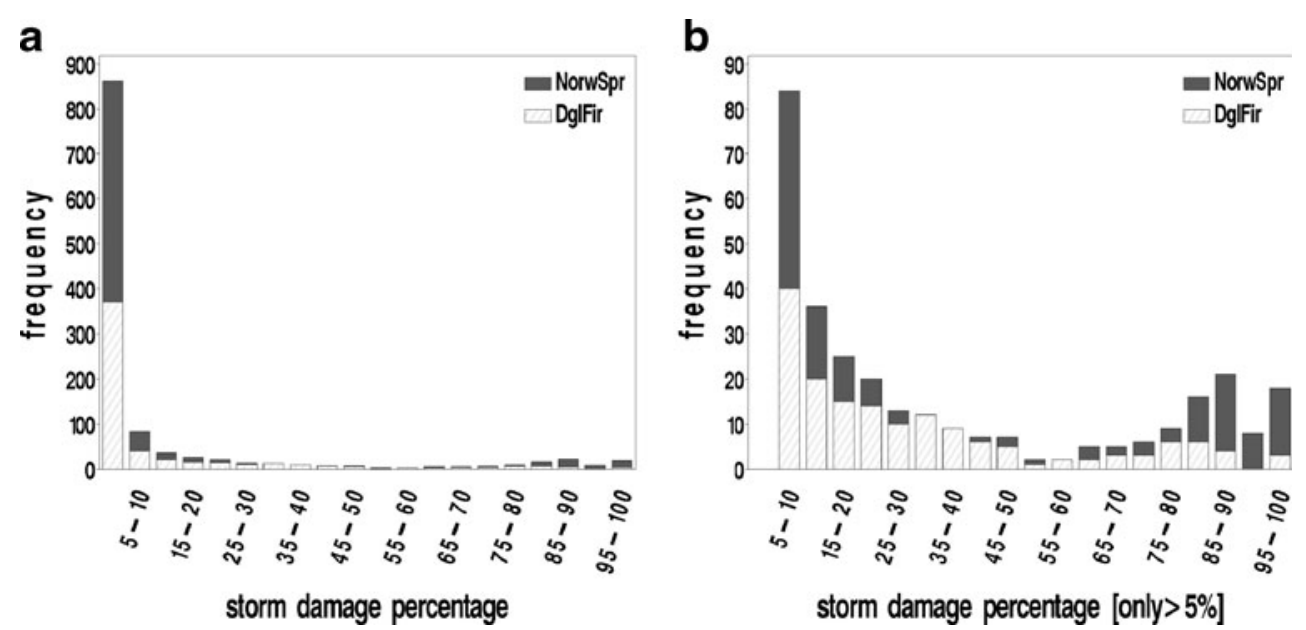

(see Eq. 1, b). Significance levels of the predictors and the signs of their coefficients are available for interpretation. The random effects component (see Eq. 1, $z^{\prime} y$ ) may account for the spatial and temporal correlation in the data and quantify their impact. Disadvantageous properties of GLMMs as opposed to BRTs are, however, that predictors must not contain critical multicollinearity and that effects of predictors must be linear (Littell et al. 2006). Nonlinear effects could be represented in nonlinear mixed models, but variable selection is often numerically impossible and model formulation is difficult when the number of candidate predictors is large $(>30)$, as in our case. We checked for multicollinearity with the variance inflation factor and found no critical values (Mayer et al. 2005).

We fit three GLMMs in a stepwise procedure to the stand-level storm damage data due to the distributional characteristics. In the first step, we modeled the general occurrence of storm damage as a binary logit model (see Eq. 2, $y \in[0 ; 1]$, where $0=$ no damage and $1=$ damage). As soon as one tree on a plot was damaged, the response of this plot was coded as 1 .

$\operatorname{Logit}(\pi)=x^{\prime} \beta+\gamma ; \quad \gamma \sim N\left(0, \sigma_{\gamma}^{2}\right)$

The random effects $(\gamma)$ quantify the spatial clustering of several plots in one trial location. They are based on the assumption that adjacent plots are more similar in characteristics than plots located in different trial locations. In mathematical terms, the errors of the adjacent plots are correlated and thus violate the assumption of independent errors (Littell et al. 2006). This leads to the formulation of a mixed model, incorporating the random effects term to account for this correlation.

In the second step, the occurrence of total stand damage among the damaged stands was modeled as a binary logit model (see Eq. 3, $y \in[0 ; 1]$, where $0=$ damage $<75 \%$ and $1=$ damage $\geq 75 \%$ ). The $75 \%$ damage threshold value was chosen based on the frequency distribution (Fig. 1) and the observation that, even in the most severely damaged stands, usually a few trees and snags are left standing. For simplification, this step will be referred to as total stand damage. The tested random effects component was nonsignificant for this second step, supposedly due to the rather small number of plots with total storm damage. This model is thus not a mixed model including random effects (GLMM) but a simple generalized linear model without random effects.

$\operatorname{Logit}(\pi)=x^{\prime} \beta$

Finally, in the third step, the amount of partial storm damage was modeled for plots with damage $>0 \%$ and $<75 \%$. This model is thus a logit model with binomial response $(y \in[0,0.75]$; relative storm damage). Random effects were again chosen to quantify the spatial clustering and the equation is thus identical to Eq. 2.

Predictors were selected in stepwise manual operation based on $p$ values with $\alpha=0.05$. As fit statistics, we used the -2 residual pseudolikelihood for the GLMMs in steps 1 and 3 . In modeling step 2 (total stand damage), we used the $-2 \log$ likelihood, which is the preferred statistic for GLMs. Unfortunately, this fit statistic is not available for GLMMs due to the correlated error structure and the resulting special likelihood approximation technique in this type of model (Littell et al. 2006, pp. 538-541, The SAS Institute Inc. 2006 , p. 119). For this reason, we used the -2 residual pseudolikelihood in steps 1 and 3 instead.

The attribute tree species was used as a categorical variable. Instead of developing separate models for each species, this approach allows the comparison of the general species-specific storm damage disposition. During the process of variable selection, we tested interactive effects between tree species and other candidate predictors. With this procedure, we examined whether the main effects vary between the species.

\subsection{Boosted regression trees}

BRTs consist of two components: decision trees and boosting algorithm. They can be seen as enhanced decision trees. 
The decision tree part is based on classification and regression trees which successively partition the data into hierarchical subgroups. One of the main results of the classification process is the split criteria for the predictors, which regroup the responses into groups of minimal within variation, but maximum between differences.

In the second part, boosting techniques are applied which successively fit many decision trees while optimizing their accuracy. Starting from the first decision tree, the following decision trees are constructed by using the residuals of the first tree as the new response variable. Within this process, the poorly modeled observations with large residuals obtain a higher weight for the next iteration. The degree of improvement in this stepwise process is measured by the deviancebased loss function. Decision trees best reducing the deviance are then selected (Friedman and Meulman 2003).

According to Elith et al. (2008), BRTs "are based on the idea that it is easier to find and average many rough rules of thumb, than to find a single, highly accurate prediction rule." They are advantageous when data are correlated, when predictor values are frequently missing, and when the number of predictors is large. Other advantages are that BRTs are insensitive to outliers and automatically account for interactions among predictors. The combination of regression trees with boosting algorithms leads to advantages which are especially relevant for our database. One important drawback of BRTs, however, is that they may have problems representing very simple relationships, such as a 1:1 line. They are more appropriate for complex data with correlations and interactions.

During the model-building process (software package R, library gbm; Ridgeway 2006), we tested varying tree sizes from 1 to 20 splits and the learning rates $0.01,0.05$, and 0.1 . We selected the combination of 10 splits (tree complexity (tc)) and a learning rate (lr) of 0.05 as the ideal parameters with minimal cross-validated deviance based on these preliminary calculations.

For interpretation of the results, partial dependence plots graphically depict the effects of each criterion under ceteris paribus conditions. Therefore, the value of the fitted function $(=\operatorname{Logit}(\pi))$ is plotted over the range of values of the respective split criterion (predictor). The dependence plots visualize the quantitative results in an easily comprehensible manner and demonstrate the shape of an effect curve, i.e., linearly increasing or decreasing effects, nonlinear or nonmonotonic effects. Furthermore, the overall importance of each split criterion is calculated for interpretation purposes as a relative value based on the number of occurrences of a predictor as a split variable weighted by its improvement of the model.

With the choice of these two methods, we have ensured that the results concerning species differences in storm vulnerability are based on one robust method representing linear effects (GLMMs) and one flexible method representing linear and nonlinear effects (BRTs).

\subsection{Relative influence of predictor categories}

To classify the numerous predictor variables, we grouped them into categories. For example, stand height, stand age, and standing volume were grouped in the category "stand dimension," while the relative amount of removed timber and the thinning quotient were grouped into the category "removals." Since the objective of the study was to investigate species effects, we also used the predictor "species" as a distinct category consisting only of this one predictor. All predictor variables and their categories are listed in Table 1.

For the GLMMs, we calculated the relative influence for each predictor by fitting a model without using the respective predictor. The loss in the fit statistic was used as an indicator for the influence of the removed predictor. Dividing that loss value by the sum of all loss values yielded the relative influence. Fortunately, the relative influence for nominal predictors like species can be calculated in the same manner as for numerical predictors.

For the BRTs, the measure of relative importance of each single predictor was averaged over all decision trees and scaled to $100 \%$, resulting in the relative influence (Friedman and Meulman 2003). Since BRTs accommodate nominal split criteria, a relative influence was also calculated for the information "species." These relative influence values were then summarized according to the predictor categories.

\section{Results}

\subsection{Preliminary analysis}

Norway spruce was, on average, slightly taller than Douglasfir (Fig. 2, left). Although some extreme values for Douglasfir surpassed the stand height of $50 \mathrm{~m}$, its mean was below $24 \mathrm{~m}$, while Norway spruce's mean dominant height was slightly above $25 \mathrm{~m}$. Displaying the dominant height separately for the two reference periods 1990 and 1999 (Fig. 2, center and right), Douglas-fir was distinctly lower for the 1990 storm than for the 1999 event.

The values of the thinning quotient of scheduled thinnings $>1$ indicate that primarily codominant and dominant trees were thinned for both species (Fig. 3a). This represents the predominantly applied selective thinning from above in favor of target crop trees. Species differences were very small and show that the thinned trees of the Norway spruce plots were slightly more dominant than those removed on the Douglas-fir plots. Differences observed for the relative scheduled removals were clearly more pronounced between 
Fig. 2 Box plots of the stand dominant height (H100) for the two species Douglas-fir $(D g l F)$ and Norway spruce (NorwSpr). Left for the total dataset, center only for the 1990 reference period, right only for the 1999 reference period
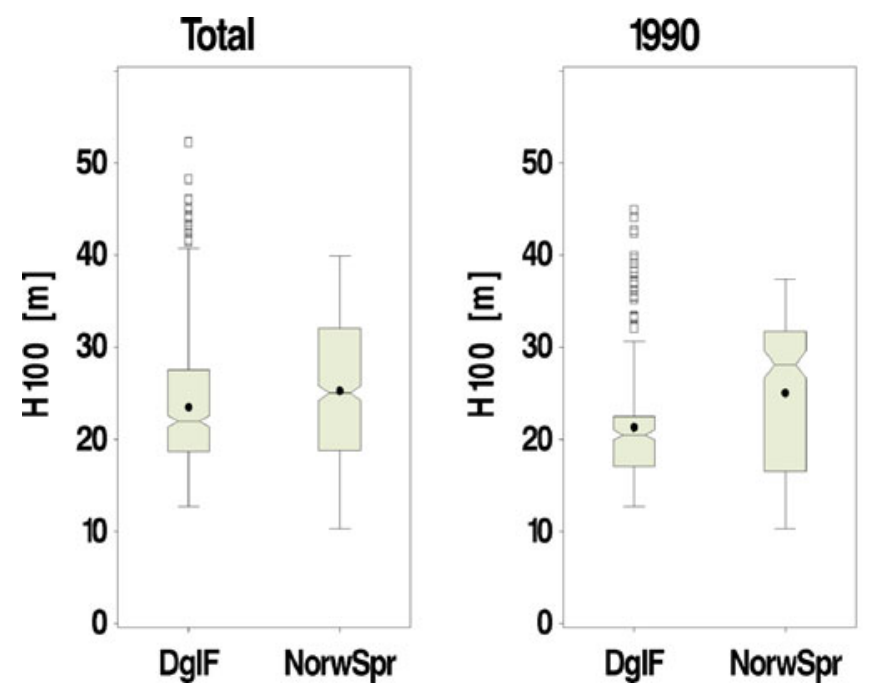

the species (Fig. 3b): On average, $17 \%$ of the standing volume was thinned from Douglas-fir plots, while only $12 \%$ were removed from Norway spruce. This means that the treatments for the two species were mainly different concerning the relative amount of removed timber and not so much in the type of thinning. Species differences for the predictors "dominant height," "thinning quotient of scheduled thinnings," and "relative removals of scheduled thinnings" were significant by the Wilcoxon test of rank sums $(\alpha=0.05)$.

Several site characteristics which have been reported in the literature to increase storm risk were analyzed for differences between Douglas-fir and Norway spruce plots. The soil type of each plot was either counted as yes or no for the six risk characteristics in Table 2. For example, $3 \%$ of all Douglas-fir plots occurred on strongly acidic soils. Thus, the values do not
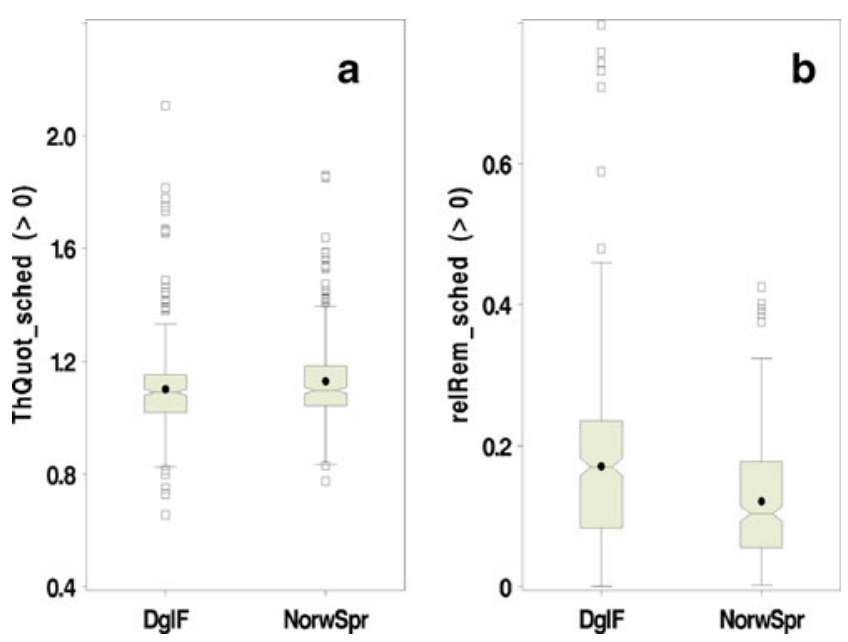

Fig. 3 Box plots for the thinning quotient of scheduled thinnings (ThQuot_sched, a) and the relative removals of scheduled thinnings (relRem_sched, b) for the two species Douglas-fir $(D g l F)$ and Norway spruce (NorwSpr) correspond to a complete distribution of soil types and consequently do not add up to $100 \%$ per species. They rather indicate what proportion of one species' plots shows a certain risk factor. The potential site risk factor "deep loam" was included in this table, since deep loams have been found to be associated with high storm damage (Dobbertin 2002; König 1995; Rottmann 1986). These authors hypothesize that deep loams bear little potential for anchorage and root grip, especially when containing high amounts of silt and small amounts of rocks and when they are water-saturated.

Douglas-fir occurred more often on clay-dominated sites $(6 \%)$ and shallow, rocky soils with restricted rooting depth (9\%). Norway spruce, however, was more frequent on strongly acidic sites, waterlogged soils, and deep loams. Both species occurred with similar frequency on soils containing free calcium carbonate.

Although the characteristics of Douglas-fir and Norway spruce plots were not exactly equal in our database, no clear species-specific trend of a priori disposition was observed in this preliminary analysis.

$3.2 \mathrm{H} 1$ : the predictor "species" is as significant for storm damage as other predictors

\subsubsection{GLMMs}

For the GLMMs in modeling step 1, three variables remained as significant predictors (Table 3 ). The positive coefficient for dominant height (H100) indicated that the probability of storm damage occurrence increased with increasing height even though this variable's relative influence was rather small. The other two predictors showed an antagonistic influence on the probability of storm damage: whereas the coefficient for the relative removed volume had a positive influence on storm damage, the coefficient for the relative removed volume of scheduled removals was 
Table 2 Site characteristics of the experimental plots

\begin{tabular}{lllllll}
\hline Species & Strongly acidic (\%) & Water-logged (\%) & Shallow soil (\%) & Free $\mathrm{CaCO}_{3}(\%)$ & Heavy clay (\%) & Deep loam (\%) \\
\hline Douglas-fir & 3 & 1 & 9 & 10 & 6 & 33 \\
Norway spruce & 29 & 12 & 5 & 11 & 1 & 53 \\
\hline
\end{tabular}

Frequency of occurrence of selected potential risk factors for Douglas-fir and Norway spruce

negative. This may indicate a stabilizing effect of scheduled removals, while all removals including salvage have a destabilizing effect. Interestingly, tree species did not have a significant influence in this modeling step, neither as a main effect nor in interaction with other predictors.

In modeling step 2, nine variables were selected as predictors explaining the occurrence of total stand damage. Dominant height (H100) had a similar positive but slightly higher influence than in modeling step 1 . The interactive effect of dominant height with "species" showed that the risk of total stand damage for Douglas-fir (DglF) increased more slowly with dominant height than for Norway spruce. Lower relative $H / D$ values were associated with less storm risk, as indicated by the positive sign of the coefficient.

Also, in step 2, scheduled removals reduced the risk of total storm damage, whereas the sum of all removals (including salvage) expressed as relative values and averaged for the preceding 10 years (relRem_10yr) indicated higher damage. Within the predictors for this modeling step, the scheduled removals had the highest relative influence. The small value of its coefficient is due to the coding of this variable in absolute values.

Increasing stock density was associated with higher total storm damage. Also, the thinning quotient of scheduled thinnings increased the probability of total storm damage. This means that the more scheduled thinnings remove trees from the dominant layer, the higher the risk of total stand damage gets.

The rather low but significant relative influence of the topex score emphasizes that orographically sheltered stands were less susceptible to storm damage (exposed locations have smaller values of this variable - the negative sign of the coefficient thus indicates the reversed scaling of this variable). Increasing speed of the modeled wind gusts for the 1990 storm was associated with higher total damage.

For the estimation of relative storm damage on the partially damaged plots (step 3 ), only two predictors proved to be significant: Firstly, elevation above sea level was negatively correlated to the amount of storm damage. This was an unexpected result which will be discussed later. In addition, increasing dominant height (H100) was associated with an increase in storm risk. Both predictors had practically equal relative influence. Again, species was not selected as a significant predictor in the model.

\subsubsection{BRTS}

The selected split criteria for the BRTs were dominated by the elevation above sea level (Table 4 ). Nearly $45 \%$ of the overall influence was explained by this variable, whereas all other variables had $<6 \%$ relative influence, respectively. The

Table 3 Selected variables and their coefficients for the GLMMs

\begin{tabular}{llllll}
\hline Modeling step & Variable & Coefficient & $p$ value & Variable category & Relative influence (\%) \\
\hline 1 (occurrence of damage) & H100 & 0.063 & 0.00 & Dimension & 1 \\
& relRem & 11.361 & 0.00 & Removals & 50 \\
& relRem_sched & -9.845 & 0.00 & Removals & 49 \\
2 (occurrence of total damage in damaged stands) & H100 & 0.126 & 0.00 & Dimension & 6 \\
& H100×species(DglF) & -0.028 & 0.00 & Species interaction & 4 \\
& hd100_relnorm_5rel & 8.295 & 0.00 & Stand density & 5 \\
& relRem_10yr & 20.008 & 0.00 & Removals & 12 \\
& Rem_sched & -0.138 & 0.00 & Removals & 43 \\
& stockDegr & 6.642 & 0.00 & Stand density & 9 \\
& ThQuot_sched & 2.084 & 0.00 & Removals & 9 \\
& Topex8w & -0.026 & 0.01 & Topography and site 3 \\
& wind90 & 0.266 & 0.00 & Meteorology & 9 \\
& elevation & -0.002 & 0.00 & Topography and site & 53 \\
\end{tabular}

For the descriptions of the variables, see Table 1 
Table 4 Selected variables for the BRTs sorted by relative influence

\begin{tabular}{ll}
\hline Variable & Relative influence (\%) \\
\hline elevation & 44.8 \\
Dist_2ForEdge & 5.7 \\
stand_age & 4.7 \\
wind99 & 4.4 \\
Rem_sched & 4.2 \\
Topex8w & 3.7 \\
wind90 & 2.7 \\
wind50 & 2.7 \\
Rem & 2.3 \\
prevStormDam & 2.3 \\
relRem_sched & 1.9 \\
stockDegr & 1.7 \\
V & 1.5 \\
relcumRemovals & 1.3 \\
yrssince_prevTh & 1.3 \\
ThQuot_sched & 1.2 \\
relRem_10yr & 1.1 \\
hd100_5rel & 1.0 \\
relRem & 1.0 \\
\hline
\end{tabular}

Only variables with relative influence $>1 \%$ are listed

distance to the westward forest edge was the second most important variable, potentially describing the effects of edges on wind turbulence and velocity at abrupt changes in the land surface. The key forest and silvicultural attributes were stand age (4.7\%), absolute scheduled removals ( $4.2 \%)$, and absolute removals $(2.3 \%)$. Similar to the GLMMs, tree species is rated with a very low influence $(0.003 \%)$.

In addition to the influence rating of the split criteria, the partial dependence plots gave further insight into the effects of each criterion. The absolute amount of removals (Fig. 4a) increased the storm risk continuously up to values of about $120 \mathrm{~m}^{3} \mathrm{ha}^{-1}$. Beyond this point, storm risk did not increase any more. If only scheduled removals were considered (Fig. 4b), a reverse effect with a leveling off near $150 \mathrm{~m}^{3}$ $\mathrm{ha}^{-1}$ was observed. The strong effect of the standing volume on storm risk showed a positive correlation (Fig. 4c) and was especially steep between 700 and $900 \mathrm{~m}^{3} \mathrm{ha}^{-1}$. The thinning quotient was also positively correlated with storm risk (Fig. 4d) up to the value of 1.2, beyond which the correlation was slightly negative but remained at a higher level than for thinning quotient values of 0.9 and smaller. Storm risk continuously increased with increasing relative removals averaged over the past 10 years (Fig. 4e). The curve reached a saturation point at $35 \%$ and remained at that high level beyond this point. Previous storm damage also increased the risk of consecutive storm damage, as indicated by the positive value of the fitted function for the $x$ value of 1 of previous storm damage (Fig. 4f). Accordingly, stands without previous damage ( $x$ value of 0 in Fig. 4f) were less at risk for consecutive damage. Notable is the abrupt step of the dependence at the value 0.5 which is typical for binary variables with only two levels $(0=$ no previous storm damage $/ 1=$ previous storm damage) .
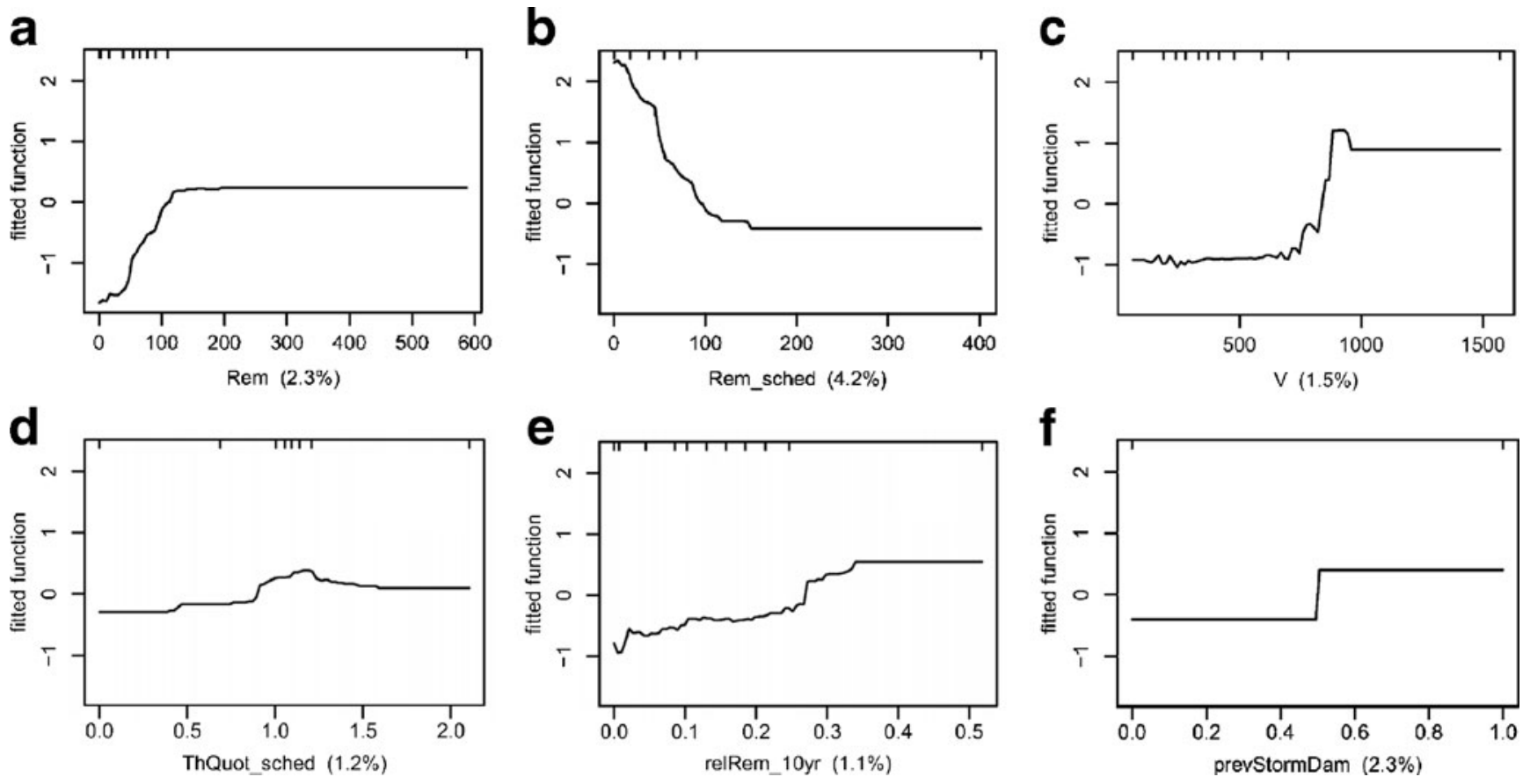

Fig. 4 a-e Partial dependence plots for six selected split criteria of the BRTs. Each subgraph plots the fitted function $(=\operatorname{Logit}(\pi))$ depending on the values/units of the respective split criterion. The short lines at the top of each graph represent the distribution (deciles) of the respective criterion as a rug plot. Values in parentheses for the abscissa labels quantify the relative influence of the criterion 


\subsubsection{Comparison of predictor categories}

Topographic and site information proved the most important predictor category in the BRT analyses, with more than $50 \%$ relative influence (Table 5). Removals were the second most important category, and meteorological information as well as stand dimension each explained about $10 \%$ of the influence. The other categories were less important and explained only up to $5 \%$.

In the GLMMs, removals were the most important category with more than $50 \%$ influence, while topography and site characteristics followed in second place. Third most important was the stand dimension. All other categoriesincluding species - carried little influence in the GLMMs.

Although both GLMM and BRT rate the two predictor categories "removals" and "topography and site" as the top two categories, their rating order is reversed. Further investigation revealed surprising coherence between the random effects (best linear unbiased predictors [BLUPs]) in the GLMM of the first modeling step and the pattern of the partial dependence plot for elevation in the BRT (Fig. 5). Both curves display a first narrow peak at elevations between 300 and $350 \mathrm{~m}$. This peak is a local maximum and is less explicit for the BLUPs (Fig. 5b) than for the BRTs (Fig. 5a). It is followed by a local minimum at $400 \mathrm{~m}$ and a second, broader peak between 500 and $620 \mathrm{~m}$. This second peak is quite apparent for both methods. Beyond $620 \mathrm{~m}$, both curves show generally decreasing patterns, with the decrease in the BLUPs more undulating and less monotonic than in the BRTs.

In summary, the relative influence of the predictor "species" is very small for both BRT and GLMM. We thus rejected hypothesis 1 . Tree species was not a significant predictor for differentiating storm damage between Douglas-fir and Norway spruce. Based on the results of both applied methods, at least five other predictor categories were rated more important.

Table 5 Relative influence of the predictor categories for the two methods BRT and GLMM

\begin{tabular}{lll}
\hline Predictor category & \multicolumn{2}{l}{ Relative influence } \\
\cline { 2 - 3 } & BRT (\%) & GLMM (\%) \\
\hline Topography and site & 54 & 19 \\
Removals & 18 & 54 \\
Meteorology & 10 & 3 \\
Dimension & 9 & 18 \\
Density & 5 & 5 \\
Previous storm damage & 2 & 0 \\
Soil & 1 & 0 \\
Species & 0.003 & 1.4 \\
\hline
\end{tabular}

\section{a}

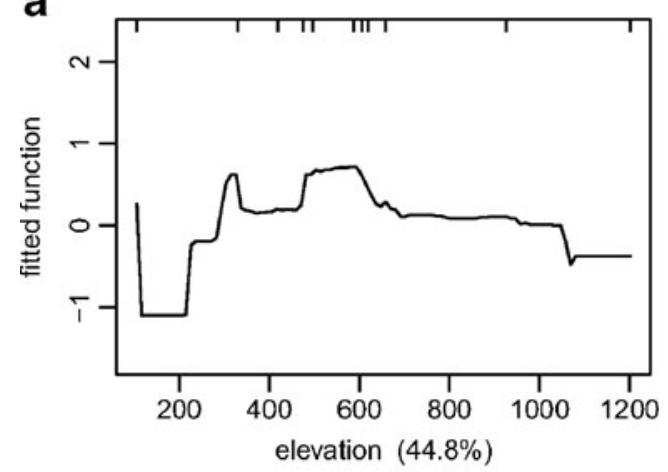

b

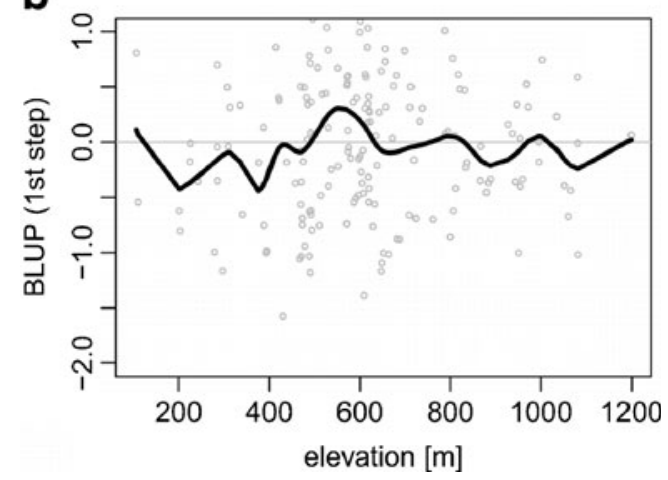

Fig. 5 Comparison of elevation effects in the BRTs and the GLMMs. a Partial dependence plot for elevation in the BRT. b Random effects (BLUPs) of the GLMM (first step) over the elevation. The line is an adjustment with a smoothing spline

3.3 H2: storm damage in Douglas-fir occurs less frequently than in Norway spruce

In total, 13,181 trees were recorded as storm-damaged from the 142,543 tree observations for both species (Table 6). In the 1990 storm, Norway spruce was more heavily damaged (7 \%) than Douglas-fir (4\%), whereas the 1999 storm caused storm damage of $15 \%$ in Douglas-fir versus only $11 \%$ in Norway spruce. However, these frequencies are only a first indication that storm damage does not occur less frequently in Douglas-fir than in Norway spruce, since they are affected by a range of other potential risk factors. For example, the lower proportion of storm damage for

Table 6 Overview of the single tree data

\begin{tabular}{lllll}
\hline $\begin{array}{l}\text { Storm } \\
\text { year }\end{array}$ & Species & $\begin{array}{l}\text { Total } \\
\text { count }\end{array}$ & $\begin{array}{l}\text { Storm-damaged } \\
\text { trees }\end{array}$ & $\begin{array}{l}\text { Proportion } \\
(\%)\end{array}$ \\
\hline 1990 & Douglas-fir & 30,556 & 1,090 & 4 \\
& Norway Spruce & 30,969 & 2,054 & 7 \\
1999 & Douglas-fir & 33,954 & 5,031 & 15 \\
& Norway Spruce & 47,064 & 5,006 & 11 \\
\hline
\end{tabular}

Total tree observations and storm-damaged trees by storm event and tree species 
Douglas-fir in the 1990 event may be in part explained by a generally lower stand height at that time (Fig. 2).

Additionally, we analyzed the random effects of the GLMMs for species differences. We compared the means and medians of the BLUPs of the modeling steps 1 and 3 but found no significant differences between Douglas-fir and Norway spruce (data not shown). This is the second indication that storm damage does not occur less frequently in Douglas-fir than in Norway spruce.

No differences between storm damage risk for Douglas-fir and Norway spruce were also detected based on the GLMM and BRT analyses. These multiple analyses included other effects like stand height or exposure and lead us to reject H1. For testing H2, this result also has significance, since lower risk of one species versus the other would have become apparent in the nominal predictor "species."

We, therefore, rejected $\mathrm{H} 2$ and concluded that storm damage in Douglas-fir is not less frequent than in Norway spruce.

\section{Discussion}

\subsection{Species effects}

If effects of stand dimension, site characteristics, and silvicultural interventions are accounted for, storm damage in Douglas-fir growing in southwest Germany appears to occur as frequently as in Norway spruce. Based on a quantitative analysis of the network of long-term experiments, there is no scientific evidence for the expectation that Douglas-fir has higher storm damage resistance than Norway spruce.

In this respect, our findings contradict the results of Schütz et al. (2006) who had found that an admixture of $10 \%$ or more of broadleaved trees or "wind-firm conifers like Douglas fir [...]" significantly reduced the vulnerability of Norway spruce stands. Riou-Nivert (2003) classified Douglas-fir as a moderately stable conifer comparable to larch (Larix decidua [Mill.] and Larix kaempferi [Lamb.] Carrière) and Corsican pines (Pinus nigra ssp. laricio [Maire]).

In support of our analysis, spruce was found to have been more stable than Douglas-fir in the 1981 storm in Denmark (Lohmander and Helles 1987). Another slight indication that Douglas-fir might not be more storm resistant than Norway spruce is the result of the empirical storm damage model by Schmidt et al. (2010). In their model, Douglas-fir displayed a higher vulnerability towards storm damage than Norway spruce up to a tree height of around $18 \mathrm{~m}$. Colin et al. (2009) classify Douglas-fir among the three most vulnerable tree species in France, based on extensive literature review. Norway spruce is the second most vulnerable species due to their findings.
As a consequence, silvicultural systems designed for Douglas-fir in Europe may need to be reconsidered due to the relatively high species-specific storm damage potential. Large target diameters associated with long rotations and tall stands have to be seen as increasing storm damage risk. In addition, stands intended for the production of large diameter timber should be restricted to orographically sheltered sites and soils without restriction for rooting depth.

\subsection{Silviculture}

Removals have a large effect on storm damage risk, as quantified by both BRT and GLMM. This influence was higher than the influence of stand dimension and density. While selective thinning has been acknowledged to have an impact on storm risk in general (Cremer et al. 1982; Dobbertin 2002; Maccurrach 1991), it has not been rated as so important before (Dhôte 2005).

Interestingly, silvicultural interventions showed both stabilizing and destabilizing effects in the short and medium term. This finding and the contradictory results for the effects of total removals (including salvage) versus scheduled removals (excluding salvage) deserve further discussion. One possible explanation for stabilization in the short term could be that thinning codominant individuals or trees with existing crown or stem damage in scheduled thinnings favors the dominant, most stable trees (Fig. 4b). Thinnings have previously been reported to stabilize coniferous stands more on the medium and long term especially by means of spacing in young ages (Cremer et al. 1982; Maccurrach 1991; Mason and Quine 1995). With respect to these previous findings, our results about possible immediate or shortterm stabilization effects are new. However, our study shows that removing higher proportions of the stands and the most dominant trees leads to short-term destabilizing effects of thinnings (Fig. 4d, e). This observed destabilization could be explained by an effect which has been reported by other authors: thinnings disrupt the crown closure, leading to more wind turbulence and leaving behind a reduced number of more exposed trees (Dobbertin 2002). In the years following the intervention, canopies close through crown expansion and the stand will be restabilized, so that this effect of destabilization is only temporary. The period of reclosure has been reported to last between 3 and 8 years (Cremer et al. 1982; Lohmander and Helles 1987; Schmid-Haas and Bachofen 1991). Thus, it appears reasonable that removals simultaneously have destabilizing and stabilizing effects, depending on the way they are carried out and on the time scale of their effects.

One possible explanation why scheduled removals had a stabilizing effect while the total removals (including salvage) indicated destabilization concerns the dominant trees. Scheduled thinnings systematically favor the target crop 
trees which are the dominant trees. Repeated thinnings from early age onwards help these individuals to acclimate to stand conditions with reduced neighbor contact (damping). Trees appearing unstable and competing with the target trees are commonly thinned. This reduces the vulnerability because unstable trees are removed. The dominant crop trees are thus important structural elements for these stands. In contrast, removals including salvage (total removals) may contain some of the crop trees as salvaged trees (storm, bark beetles), as is apparent by the thinning quotients for scheduled and total removals (Table 1). Caused by these disturbances, some of the important dominant trees are removed from the stands, leaving behind an increased amount of trees which are not acclimated to the more open growing conditions. Additionally to the effect of acclimatization (Telewski 1995), disturbances may create larger patches of irregular spatial distribution in the stands, leading to increased turbulences compared to scheduled thinnings. This may lead to a higher amount of storm damage in the consecutive periods and explains why total removals including salvage have destabilizing effects, whereas scheduled thinnings have stabilizing effects.

\subsection{Topography}

Although both GLMM and BRT rate the two predictor categories "removals" and "topography and site" as the top two categories, their rating order is reversed. This reversed order may be explained by the applied methods: A nonlinear effect of elevation was observed in both GLMMs and BRTs (Fig. 5). However, in the GLMMs, this effect was expressed in the random effects part of the model and was thus not represented in the relative influence, since the relative influence can only be calculated for the fixed effects. Hypothetically, trying to weigh this random effect of the GLMMs into the relative influence and viewing it as belonging to the category of topography and site would increase the relative influence of this predictor category for the GLMMs in Table 5. As a consequence, the observed difference between the BRT and GLMM ratings for the top two categories (topography and site, removals) would be reduced.

Since wind speed is known to increase with elevation, storm damage may be expected to increase with elevation as well. However, in our results, the effect of elevation on storm damage was nonlinear (BRTs and BLUPs in GLMM) and negatively linear (step 3 in GLMM). Lanquaye-Opoku and Mitchell (2005) also found a negative correlation between elevation and storm damage on cutblock edge segments. One reason for this phenomenon could be the adaptive growth of trees in windy locations. Reduced height growth and increased root and diameter growth as a reaction to windexposed locations has been demonstrated (Cremer et al. 1982; Nicoll et al. 2008). These physiological reactions might reduce storm damage in windy locations and thus dampen the effect of elevation. We also checked for correlations between elevation and treatment regimes in our data (thinning quotient and relative removals), since such correlations could have blurred the relationship between elevation and storm damage. But we found no significant correlation. Finally, there are many other aspects which might be relevant for the relationship between elevation and storm damage which we were not able to analyze in our study, such as interactions between wind gust speed characteristics and topographic information (see Lanquaye-Opoku and Mitchell 2005).

Acknowledgments The authors would like to thank Dr. Edgar Kublin for statistical consulting and Ms. Robin Hillestad for native English language reviewing of this publication.

Funding This study was partly funded by the German Federal Ministry of Education and Research under funding code 0330622 and by the Forest Research Institute Baden-Württemberg. The authors are responsible for the contents of this publication.

\section{References}

Albrecht A (2009) Sturmschadensanalysen langfristiger waldwachstumskundlicher Versuchsflächendaten in Baden-Württemberg. Dissertation, University of Freiburg

BMVEL (2006) Results from the National Forest Inventory 2001/2. German Federal Ministry of Food, Agriculture and Consumer Protection. Available at http://www.bundeswaldinventur.de/enid/ 98bb5c5ea761ec258d9e6e619a27f9b2,0/76.html. Accessed 7 September 2012

Bouchon J (1987) État de la recherche relative aux dégâts forestiers dus aux tempêtes. Rev For Fr 39:301-312

Colin F, Vinkler I, Riou-Nivert P, Renaud J-P, Hervé J-C, Bock J, Piton B (2009) Facteurs de risque de chablis dans les peuplements forestiers: les leçons tirées des tempêtes de 1999. In: Birot Y, Landmann G, Bonhême I (eds) La forêt face aux tempêtes. Quae Editions, Versailles, pp 177-228

Cremer KW, Borough CJ, McKinnel FH, Carter PR (1982) Effects of stocking and thinning on wind damage in plantations. N Z J For Sci 12:244-268

Cucchi V, Meredieu C, Stokes A, Coligny FD, Suarez J, Gardiner BA (2005) Modelling the windthrow risk for simulated forest stands of maritime pine (Pinus pinaster Ait.). For Ecol Manag 213:184-196

Dhôte J-F (2005) Implication of forest diversity in resistance to strong winds. In: Scherer-Lorenzen M, Körner C, Schulze E-D (eds) Forest diversity and function. Springer, Berlin, pp 291-307. doi:210.1007/1003-1540-26599-26596_26514

Dobbertin M (2002) Influence of stand structure and site factors on wind damage comparing the storms Vivian and Lothar. For Snow Landsc Res 77:187-205

Elith J, Leathwick JR, Hastie T (2008) A working guide to boosted regression trees. J Anim Ecol 77:802-813

Enke W, Deutschländer T, Schneider F, Küchler W (2005) Results of five regional climate studies applying a weather pattern based downscaling method to ECHAM4 climate simulation. Meteorol Z 14:247-257

Friedman JH, Meulman JJ (2003) Multiple additive regression trees with application in epidemiology. Stat Med 22:1365-1381

Groth O (1927) Die Wurzelbildung der Douglasie und ihr Einfluß auf die Sturm- und Schneefestigkeit dieser Holzart. Offprint Allg For Jagdztg 103 (in German) 
Hanewinkel M (2005) Neural networks for assessing the risk of windthrow on the forest division level: a case study in southwest Germany. Eur J For Res 124:243-249

Heidingsfelder A, Knoke T (2004) Douglasie versus Fichte. J.D. Sauerländer's Verlag, Frankfurt am Main (in German)

Heneka P, Hofherr T, Ruck B, Kottmeier C (2006) Winter storm risk of residential structures - model development and application to the German state of Baden-Württemberg. Nat Hazards Earth Syst Sci 6:721-733

Hermann RK (2005) Wurzelstudien an Douglasie - ein Literaturüberblick. In: Dong PH (ed) Zum Anbau und Wachstum der Douglasie. Mitt Forsch Anst Waldökologie Forstwirtsch Rheinl-Pfalz 55:135-164 (in German)

Johnson M, Kohler G, Omdal D, Kroll A R, Ripley K, Hostetler B, Mathison R, Nelson A (2010) Forest health highlights in Washington 2009. DNR WA, Forest Health Program. Available at http://www.dnr.wa.gov/Publications/rp_fh_2009_forest health highlights.pdf. Accessed 7 September $\overline{2} 01 \overline{2}$

König A (1995) Sturmgefährdung von Beständen im Altersklassenwald. Dissertation, Technical University of Munich (in German)

Lanquaye-Opoku N, Mitchell SJ (2005) Portability of stand-level empirical windthrow risk models. For Ecol Manag 216:134148

Leckebusch G, Koffi B, Ulbrich U, Pinto JG, Spangehl T, Zacharias S (2006) Analysis of frequency and intensity of European winter storm events from a multi-model perspective, at synoptic and regional scales. Clim Res 31:59-74

Littell RC, Milliken GA, Stroup WW, Wolfinger RD, Schabenberger O (2006) SAS for mixed models, 2nd edn. SAS Institute Inc., Cary

Lohmander P, Helles F (1987) Windthrow probability as a function of stand characteristics and shelter. Scand J For Res 2:227-238

Maccurrach RS (1991) Spacing: an option for reducing storm damage. Scott For 45:285-297

Mason WL, Quine CP (1995) Silvicultural possibilities for increasing structural diversity in British spruce forests: the case of Kielder Forest. For Ecol Manag 79:13-28

Mayer P, Brang P, Dobbertin M, Hallenbarter D, Renaud J-P, Walthert L, Zimmermann S (2005) Forest storm damage is more frequent on acidic soils. Ann For Sci 62:303-311

Mayhead GJ (1973) Some drag coefficients for British forest trees derived from wind tunnel studies. Agric Meteorol 12:123-130

McComb WC, Spies TA, Emmingham WH (1993) Douglas-fir forestsmanaging for timber and mature-forest habitat. J For 91:31-42

McMinn RG (1963) Characteristics of Douglas-fir root systems. Can J Bot 41:105-122

Nicoll BC, Gardiner BA, Peace AJ (2008) Improvements in anchorage provided by the acclimation of forest trees to wind stress. For 81:389-398

Nicoll BC, Gardiner BA, Rayner B, Peace AJ (2006) Anchorage of coniferous trees in relation to species, soil type, and rooting depth. Can J For Res 36:1871-1883
Quine C (1995) Assessing the risk of wind damage to forests: practice and pitfalls. In: Coutts MP, Grace J (eds) Wind and trees. Cambridge University Press, Cambridge, pp 379-403

Rich RL, Frelich LE, Reich PB (2007) Wind-throw mortality in the southern boreal forest: effects of species, diameter and stand age. J Ecol 95:1261-1273

Ridgeway G (2006) Generalized boosted regression models. Documentation on the R package "gbm". Available at http://cran.rproject.org/web/packages/gbm/gbm.pdf. Accessed 7 September 2012

Riou-Nivert P (2003) Tempêtes et dégâts aux forêts : évolution sur le $\mathrm{XXe}$ siècle. Programme International Géosphère BiosphèreProgramme Mondial de recherches sur le climat (PIGB-PMRC) $15: 46-49$

Rottmann M (1986) Wind- und Sturmschäden im Wald. J.D. Sauerländer's Verlag, Frankfurt am Main (in German)

Rudnicki M, Mitchell SJ, Novak MD (2004) Wind tunnel measurements of crown streamlining and drag relationships for three conifer species. Can J For Res 34:666-676

Schmid-Haas P, Bachofen H (1991) Die Sturmgefährdung von Einzelbäumen und Beständen. Schweiz Z Forstwes 142:477504 (in German)

Schmidt M, Hanewinkel M, Kändler G, Kublin E, Kohnle U (2010) An inventory-based approach for modeling single tree storm damage - experiences with the winter storm 1999 in southwestern Germany. Can J For Res 40:1636-1652

Schütz J-P, Götz M, Schmid W, Mandallaz D (2006) Vulnerability of spruce (Picea abies) and beech (Fagus sylvatica) forest stands to storms and consequences for silviculture. Eur J For Res 125:291-302

Spiecker H, Mielikäinen K, Koehl M, Skovsgaard JP (eds) (1996) Growth trends in European forests: studies from 12 countries. Springer, Berlin

Stock M (ed) (2005) Klimawandel-Auswirkungen, Risiken, Anpassung. Potsdam Institute of Climate Impact Research, PIK Report (99) (in German)

Studholme WP (1995) The experience of and management strategy adopted by the Selwyn Plantation Board, New Zealand. In: Coutts MP, Grace J (eds) Wind and trees. Cambridge University Press, Cambridge, pp 468-476

Telewski FW (1995) Wind-induced physiological and developmental responses in trees. In: Coutts MP, Grace J (eds) Wind and trees. Cambridge University Press, Cambridge, pp 237-263

The SAS Institute Inc (2006) The GLIMMIX procedure-June 2006. Available at http://support.sas.com/rnd/app/papers/glimmix.pdf. Accessed 7 September 2012

Von Teuffel K, Heinrich B, Baumgarten M (2004) Present distribution of secondary Norway spruce in Europe. In: Spiecker H, Hansen J, Klimo E, Skovsgaard JP, Sterba H, Von Teuffel K (eds) Norway spruce conversion - options and consequences. Brill, Leiden

Vollsinger S, Mitchell SJ, Byrne KE, Novak MD, Rudnicki M (2005) Wind tunnel measurements of crown streamlining and drag relationships for several hardwood species. Can J For Res 35:1238 1249 